\title{
Effects of Adding Nanosilica on Performance of Ethylsilicat (TEOS) as Consolidation and Protection Materials for Highly Porous Artistic Stone
}

\author{
Mohammad A. Al-Dosari ${ }^{1 *}$, Sawsan Darwish ${ }^{2}$, Mahmoud Abd El-Hafez ${ }^{2}$, Nagib Elmarzugi ${ }^{3}$, Nadia \\ Al-Mouallimi $^{4}$ and Sayed Mansour ${ }^{2,5}$ \\ 1. Department of Conservation, Faculty of Archaeology, Cairo University, Giza, P. O. Box 12613, Egypt \\ 2. Faculty of Pharmacy, Tripoli University \& National Nanotechnology Project, Biotechnology Research Center, LARST, P. O. Box \\ 13100, Tripoli, Libya \\ 3. National Nanotechnology Research Center, King Abdulalziz City for Science and Technology (KACST), P. O. Box 6086, Riyadh, \\ Saudi Arabia \\ 4. Saudi Nano Information Center, Jeddah P. O. Box 20718, Saudi Arabia \\ 5. The Grand Egyptian Museum, Ministry of Antiquities, Cairo, P. O. Box 12561, Egypt
}

\begin{abstract}
Historical sandstone surfaces and architectural heritage may undergo unwanted changes due to the exposure to many mechanical, physical and chemical deterioration factors. This paper evaluates the effectiveness of inorganic compatible treatments; Based on nanoparticles of silica $\left(\mathrm{SiO}_{2}\right)$ dispersed in silicon based product, commonly used as a water-repellent/ consolidation for the decayed construction materials. The nanocomposites obtained by dispersing the silica nanoparticles in polymeric matrices SILRES ${ }^{R}$ BS OH 100 (solventless mixtures of ethyl silicates (TEOS) tetraethoxysilane) were used to improve the physiochemical and mechanical properties of the stone material. The nanocomposites and pure SILRES ${ }^{\circledR}$ BS OH 100 were applied by brush on experimental sandstone blocks. Scanning electron microscopy coupled with energy dispersive X-ray microanalysis (SEM-EDX), polarized transmitted light microscopy (PLM), X-ray diffraction (XRD), capillary water absorption measurements, colorimetric measurements and compressive strength tests were used in performing the study. The results showed that silica/polymer nanocomposite is an efficient material for the consolidation of artistic and architectural sandstone monuments, completely compatible, enhanced the durability of sandstone. In addition, the obtained nanocomposite improved the stone mechanical properties and the resistance to the effects of the erosion, acids and salts compared to the samples treated with pure SILRES® BS OH 100 without silica nanoparticles.
\end{abstract}

Key words: Sandstone monuments, silica nanoparticles, consolidation, nanocomposites, colorimetric measurements, compressive strength, stone artworks.

\section{Introduction}

Sandstones are very important in the building elements of world's historical and cultural heritage [1]. In particular, the sandstones were widely used to build most of historical buildings in Upper Egypt and Egyptian oasis (temples, monasteries, tombs and

*Corresponding author: Mohammad Al-Dosari, associate research professor, research fields: chemistry and nanotechnology. churches). However, due to their prevalently outdoor location and the high porosity of the sandstone, they are generally subjected to a complex series of weathering and decaying processes such as the natural environment, high ratio of sun rays, mechanical and physical factors as well as artificial damages. The previous factors lead to severe weathering of the exposed surfaces [2-6].

It is necessary to understand the mechanisms responsible for the stone decay to optimize stone 
protection strategies $[7,8]$. The stone degradation mechanisms are controlled by several factors as mineral composition, textural characteristics and pore/capillary structure [9]. In this study, the ancient temples in Kharga oasis located in the vast desert environment, which is surrounded by plateaus and highlands sand with oases climate. This climate is usually hot dry in summer, warm in winter with scarcity of rain. The oasis is characterized by the highest ratio of the brightness of the sun in the world. The deterioration takes the form of loss and granular disintegration of the surface layers of sandstone. This phenomenon is formed due to the dissolution of the binding materials between the grains of quartz. Winds and sometimes rain water combine with salts dispersed in the surrounding environment or accumulated in the core of the monument itself producing crystallization pressures, which weaken the bonds between the grains in the stone [10-12]. This process causes diverse deterioration aspects such as granular disintegration, exfoliation, detachment, erosion, cracking, deformation, efflorescence, discoloration, different microbiological colonization and finally loss of the monuments which were carved or constructed from this stone [13-15].

In the last decade, nanomaterials and various synthetic nanocomposites with better chemical, physical and mechanical properties than conventional ones have been widely used in consolidation and protection of stone artworks [16, 17]. Application of them as consolidation and protection agents for sand stone has been carried out to provide hydrophobic, consolidation and protection property to highly porous stone. The dispersion of nanoparticles in the polymers used in the consolidation and protection processes leads to a significant enhancement of their physiochemical and mechanical properties [18-22].

Silica nanoparticles are recent and important type of nano-products [23]. They have several advantages such as stability, low toxicity and ability to be functionalized with a range of molecules and polymers [24, 25]. Generally, silica is used in consolidation treatments. It can be compacted with sandstone composition to reduce the porosity of stone substrates. Therefore, it controls the deterioration action of binding materials in sandstone structure, enhances the hydrophobic character of sandstone surface, as well as controlling the swelling action of clays, and improves the physio mechanical properties of treated sandstone [26-28].

In order to assess the effect of the treatment materials, untreated, treated and treated thermally aged samples were evaluated comparatively by using different methods. Scanning electron microscopy (SEM) examination is performed to evaluate penetration depth, re-aggregating effects of the deposited phase and the surface morphology. Improvements of stone mechanical properties were evaluated by compressive strength tests. Changes in water-interaction properties were evaluated by water absorption capillarity measurements. Colorimetric measurements were used to evaluate the optical appearance. The results proved that the addition of silica nanoparticles into the silicon-based polymers produced a significant improvement in consolidation and protection of the sandstone samples.

Therefore, the present work focused on increasing the efficiency of the conventional materials by adding silicon dioxide nanoparticles to silicon polymer (SILRES ${ }^{\circledR}$ BS OH 100 (solventless mixtures of ethyl silicates), commonly used as a water-repellent/ consolidation for the construction materials. This nanocomposite was carried out to achieve higher consolidation, protection, hydrophobic efficiency and to improve the properties of the sandstone samples.

\section{Materials and Methods}

\subsection{Materials}

2.1.1 Studied Sandstone Samples and Historical Site

Al-Nadora hill is located in Kharga oasis, western desert, Egypt. It is located on the southeast side of "Hibs" temple area, about one kilometer, the temple. 
Al-Nadora was built in roman times, there are many inscriptions refer to the name of emperor "Antoninos peyos". The name "Al-Nadora" was named by the Arabs, because this region, up from ground level, about 75 meters, the man who climbs on top of this hill can see the whole city of Kharga oasis. In the ancient times, the Arabs have used this site to observe the enemies. In the Mamluk era, this area was used as an observatory to the trade caravans that pass on "Darb Al-Arbien".

The temple was exposed to many physical and mechanical deterioration factors as result of its location in desert environment and desert climate as mentioned above. The deterioration takes the form of loss and granular disintegration, exfoliation, detachment, erosion, as well as missing parts and loss of some walls and layers from temple walls. The temple was built basically of sandstone blocks. The external walls and some attached rooms were built of mud bricks. The sandstone samples were carefully picked up from the fallen fragments of temple walls, see Fig. 1.

\subsubsection{Chemicals}

The protective products tested in this work were:

SILRES ${ }^{\circledR}$ BS OH 100 (solventless mixtures of ethyl silicates) was used as supplied by Wacker Silicons (Germany). It is commonly used as water-repellent/consolidants material.

An aqueous colloidal solution of silica nanoparticles were purchased from Sigma Aldrich (particle mean diameter $<50 \mathrm{~nm}$, see Fig. 2).

\subsection{Methods}

2.2.1 Preparation of Silica/Polymer Nanocomposites

The blends were prepared by direct mixing of polymer and nanoparticles. The procedure consists of dispersing the colloid of silica nanoparticles in an aqueous suspension of silicon-based polymer (3\% $\mathrm{w} / \mathrm{v})$. Dispersions were stirred vigorously for $45 \mathrm{~min}$, and then were applied on the samples by brushing.

\subsubsection{The Stone Treatments}

The experimental sandstone specimens were small cubes with $3 \mathrm{~cm} \times 3 \mathrm{~cm} \times 3 \mathrm{~cm}$. After the cutting and cleaning with a soft brush, the samples were washed with deionized water in order to remove the stone dust. Then they were dried in an oven at $105{ }^{\circ} \mathrm{C}$ for $24 \mathrm{~h}$. The protective products tested in this work were applied by brushing at room pressure and temperature. The operation was repeated three times within an hour between each application. The treated samples were left to dry off for 21 days at room temperature and controlled $\mathrm{RH} 50 \%$ to allow the polymerization process to take place. Some of treated samples were submitted to investigation methods and the others were submitted to the artificial aging and then to the investigation methods to monitor the changes of protective materials after accelerated aging test.

\subsubsection{Artificial Aging}

Artificial aging aims to simulate the actual environmental deteriorating conditions and to quantify the durability of the treatments. Two types of weathering-mentioned below were conducted sequentially and termed as "artificial aging".

\subsubsection{Thermal Aging Cycles}

Thermal aging was selected to simulate the natural conditions in which the historical site in Kharga oasis exists and to know the effect of high ratio of sun rays and water on the rock. Thus, this test consisted of 30 cycles of immersion and drying as follows: $18 \mathrm{~h}$ of total immersion in distilled water then $6 \mathrm{~h}$ in a temperature-controlled oven "Herous-Germany" on special frames at $105^{\circ} \mathrm{C}[29]$.

\subsubsection{Salt Crystallization Weathering}

The samples were subjected to cycles of immersion in a saturated $\mathrm{Na}_{2} \mathrm{SO}_{4}$ solution for $4 \mathrm{~h}$ followed by $28 \mathrm{~h}$ of exposure to air in normal room conditions ( 25 ${ }^{\circ} \mathrm{C}$ and $40 \%$ R.H.) then $16 \mathrm{~h}$ in an oven at $105^{\circ} \mathrm{C}$ [30, $31]$.

2.2.4 Microscopic Examination

Thin sections were used for identification of stone minerals by using polarized transmitted light microscopy 
Effects of Adding Nanosilica on Performance of Ethylsilicat (TEOS) as Consolidation and Protection Materials for Highly Porous Artistic Stone

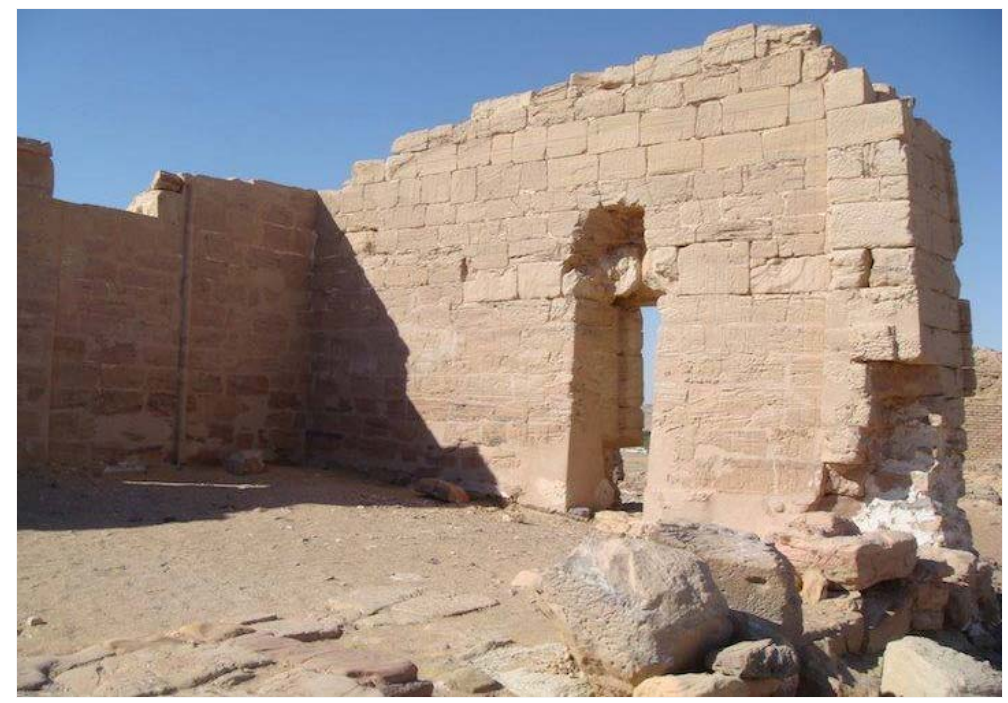

(a)

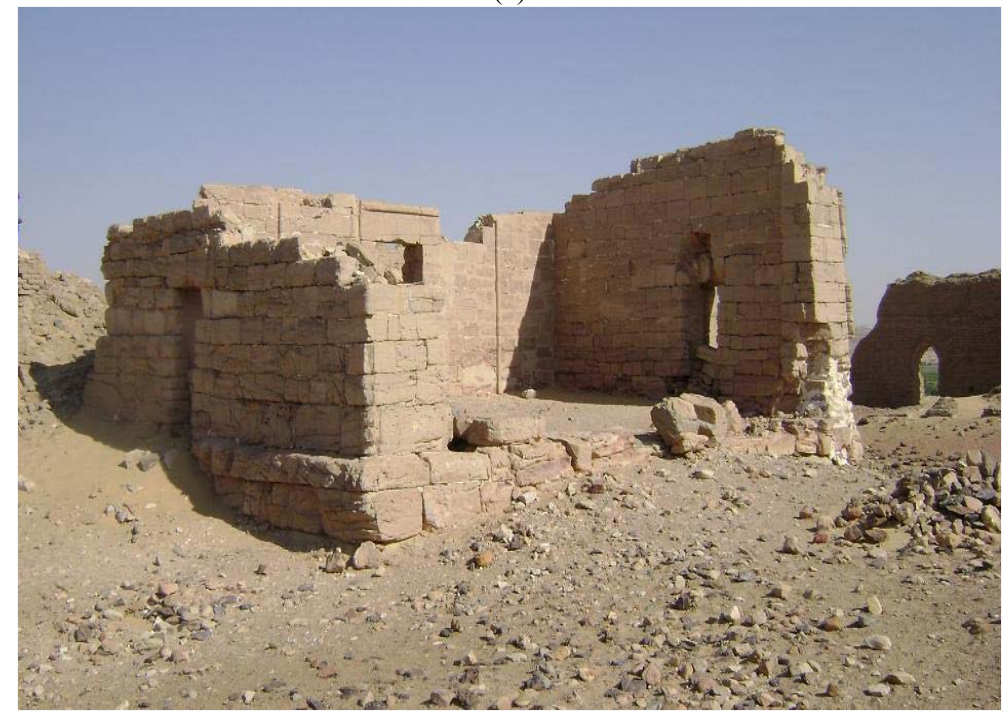

(b)

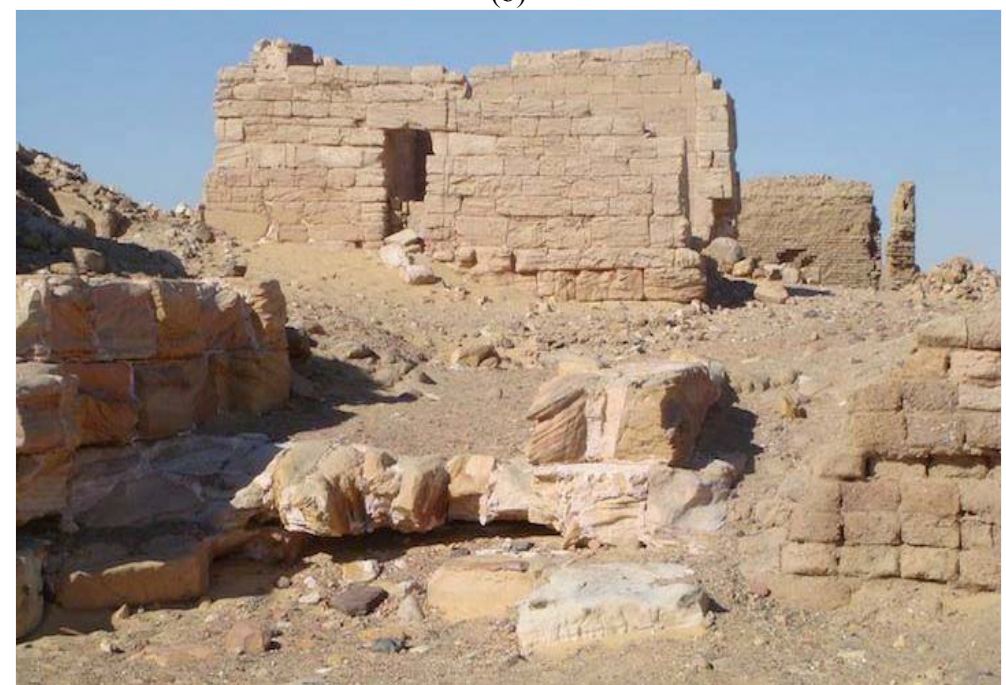

(c)

Fig. 1 (a)-(c) Al-Nadora temple and its fallen parts. 


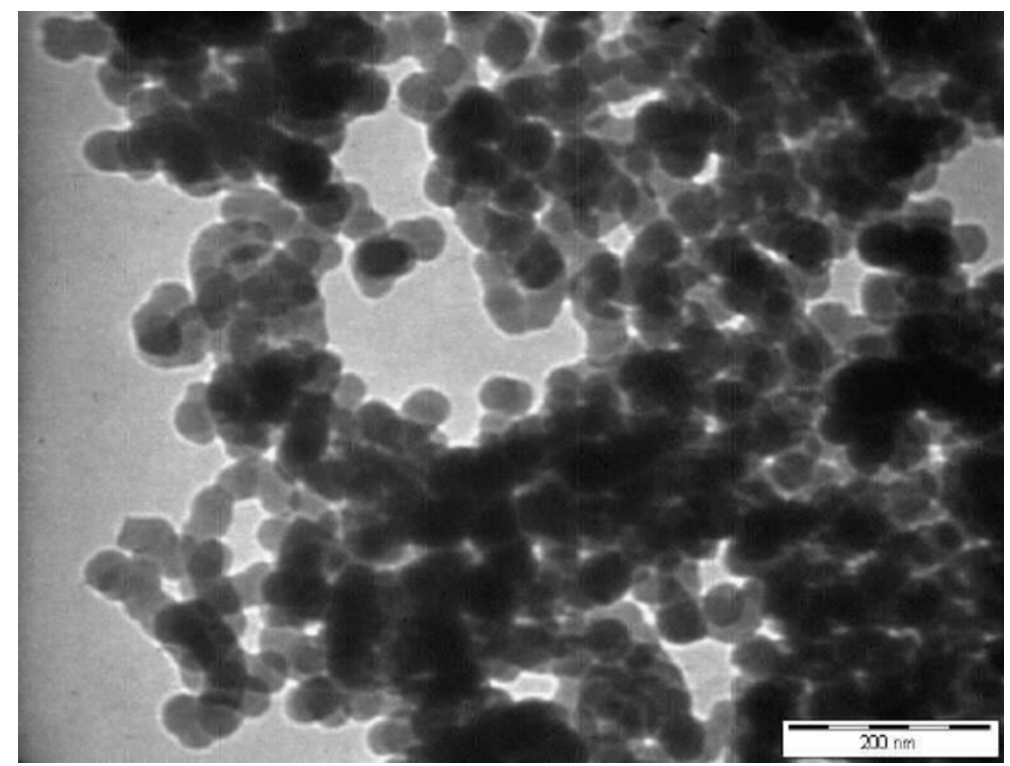

Fig. 2 TEM micrograph of the silica nanoparticles $(<50 \mathrm{~nm})$.

(PLM), model Nikon opti photo X23 equipped with photo camera S23, under $30 \mathrm{X}$ magnifications in plane-polarized light.

The microstructure of the untreated treated and treated aged samples, were observed by SEM, Philips (XL30) equipped with EDX micro-analytical system. This examination was performed to detect the element contents of archaeological sandstone samples, in addition to determine the morphology of the particles, voids, weathering status of the particles and cracks of coating after treatment with polymer and to evaluate the distribution, penetration and behavior of the consolidants on treated and treated aged samples. Images were acquired in backscattered mode (BSE).

\subsubsection{X-Ray Diffraction (XRD)}

Identification of the mineral composition of the samples was conducted by X-ray diffraction patterns, using A "Philips" X-ray diffractometer (PW 3071) $(\mathrm{CuK} \alpha 40 \mathrm{kV}, 30 \mathrm{~mA})$. The scanned 2theta range was 5 to 60 degrees.

\subsubsection{Colorimetric Measurements}

Colorimetric measurements were carried out on untreated, treated and treated aged sandstone sample using a CM-2600d Kon-ica Minolta spectrophotometer to assess chromatic variations. Chromatic values are expressed in the CIE $\mathrm{L}^{*} \mathrm{a} * \mathrm{~b}^{*}$ space, where $\mathrm{L}^{*}$ is the lightness/darkness coordinate $(100=$ white, $0=$ black $), a^{*}$ the red/green coordinate $\left(+a^{*}\right.$ indicating red and $-a^{*}$ green) and $b^{*}$ the yellow/blue coordinate $\left(+b^{*}\right.$ indicating yellow and $-b^{*}$ blue). [32, 33].

\subsubsection{Physical Properties}

Bulk density, porosity and water absorption were determined before and after treatment with consolidants. In each test, three treated-samples were compared against three untreated-samples. The water absorption measurements were carried out using the gravimetric method before and after treatment, as well as after artificial aging process, the tests were applied on stone samples measuring $3 \mathrm{~cm} \times 3 \mathrm{~cm} \times 3 \mathrm{~cm}$. The sandstone samples were completely immersed in deionized water at room temperature. After $24 \mathrm{~h}$, the samples were taken out, wiped with tissue paper carefully and weighed immediately. [34-36]. The values of density, porosity and the amount of the absorbed water were calculated using the following equations:

$$
\begin{aligned}
& \operatorname{Density}\left(\mathrm{gm} \cdot \mathrm{cm}^{-3}\right)=\frac{W}{V} \\
& \operatorname{Porosity}(\%)=\frac{W_{2}-W_{1}}{V}
\end{aligned}
$$




$$
\text { Water absorption }(\%)=\frac{\left(W_{2}-W_{1}\right)}{W_{1}} \times 100
$$

where, $W$ is sample weight, $V$ is sample volume, $W_{2}$ is the mass of the sample after immersion in water for 24 $\mathrm{h}$, and $W_{l}$ is the mass of the sample before immersion.

\subsubsection{Mechanical Properties}

The measurement of compressive strength of the untreated, treated and treated aged sandstone sample were carried out using an Amsler compression-testing machine, with the load applied perpendicular to the bedding plane. According to ASTM C 170, the compressive strength test was carried out on three sandstone cubes $\left(5 \mathrm{~cm}^{3}\right)$ [37] and the average values of compression strength were recorded.

\section{Results and Discussion}

\subsection{Characterization of Studied Sandstone Material}

\subsubsection{Mineralogical Composition}

Polarizing microscope observation of sandstone. Fig. 3 showed that it consists mainly of white grains of quartz crystals in addition to high ratio of iron oxides and clay minerals. P.M. Microscopic photo showed degradation in the mineralogical components of sandstone, especially quartz and iron oxides. SEM microscopic photos of the sandstone sample in Figs. $4 \mathrm{a}$ and $4 \mathrm{~b}$ showed high porosity of sandstone and roundness of Quartz crystals due to degradation by physical weathering and salt crystallization. The total
EDX analysis of the sandstone samples in Fig. 4c showed that silicon $(\mathrm{Si})$, calcium $(\mathrm{Ca})$ and potassium (K) are the dominant elements; Iron (Fe) and sulfur (S) were observed.

3.1.2 X-Ray Diffraction (XRD) Data of Sandstone Samples.

Fig. 5 showed that it consists essentially of quartz $\left[\mathrm{SiO}_{2}\right]$ as a major mineralogical constituent, with trace amounts of the following minerals: Iron Oxides, Calcite, Halite and Kaolinite.

\subsection{Evaluation of Selected Consolidation Materials for Sandstone Conservation}

\subsubsection{SEM Investigations}

Morphological observations by Environmental Scanning Electron Microscopy (ESEM, Mod. XL30, Philips Company) were performed in order to study the distribution of the treatments on the stone surface, detect the penetration depth of the consolidation materials within the stones and study the ability of the consolidation materials to consolidate and protect the sandstone samples. The SEM images of the samples were shown in Figs. 6a-6e. The SEM micrographs of the untreated sample in Fig. 6a showed the inhomogeneous structure of the fine-grained quartz mineral, the binding material and kaolinite crystals. The presence of some voids and disintegration were also noticed because of dissolving and disappearance of

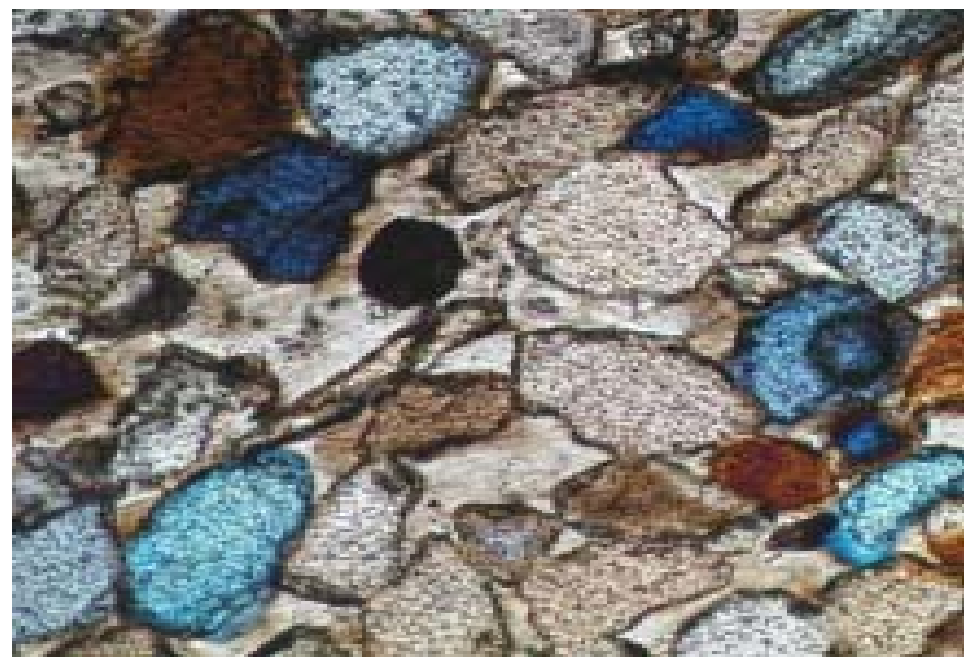

Fig. 3 Thin section of sandstone- Al-Nadora temple, (X30. crossed nicols). 

Protection Materials for Highly Porous Artistic Stone

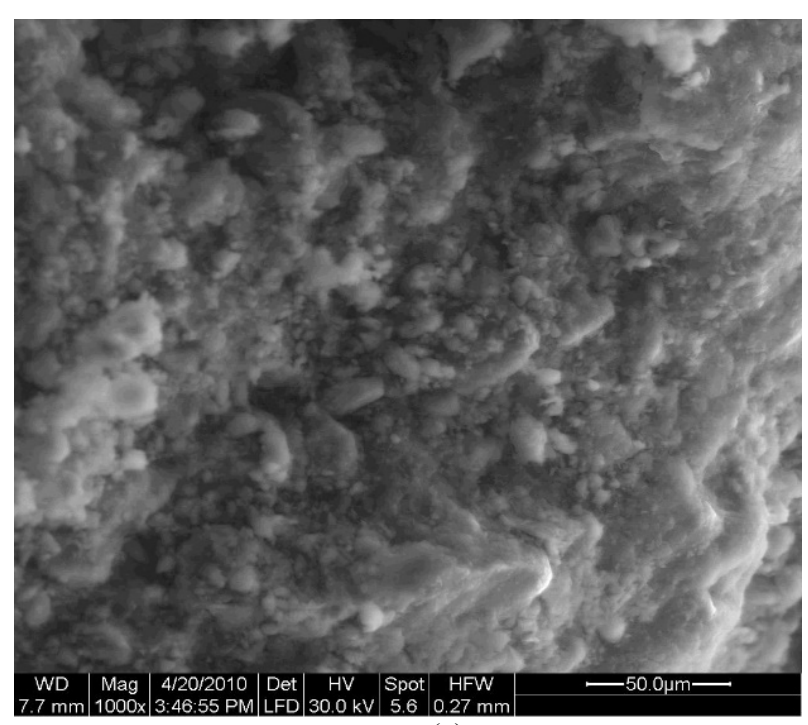

(a)

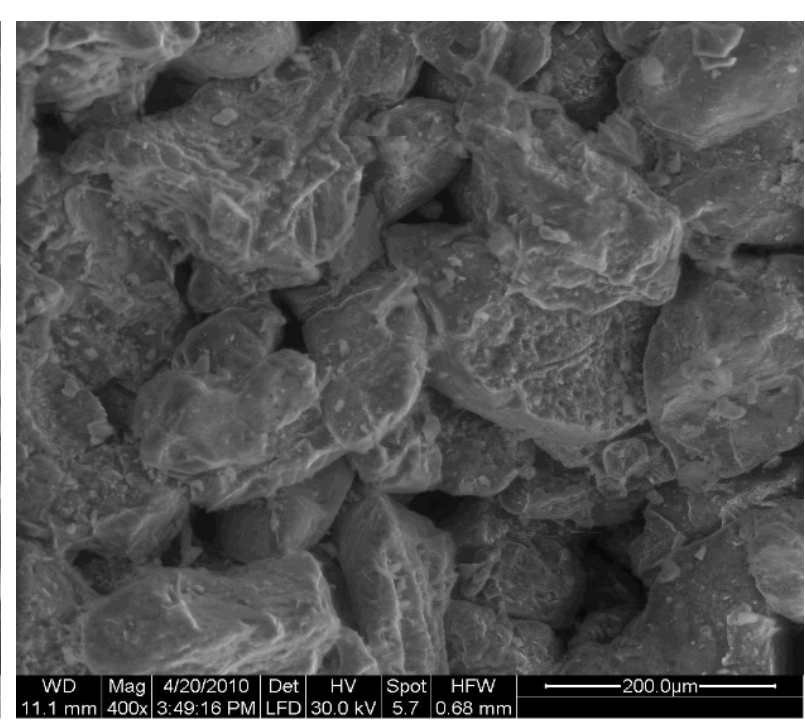

(b)

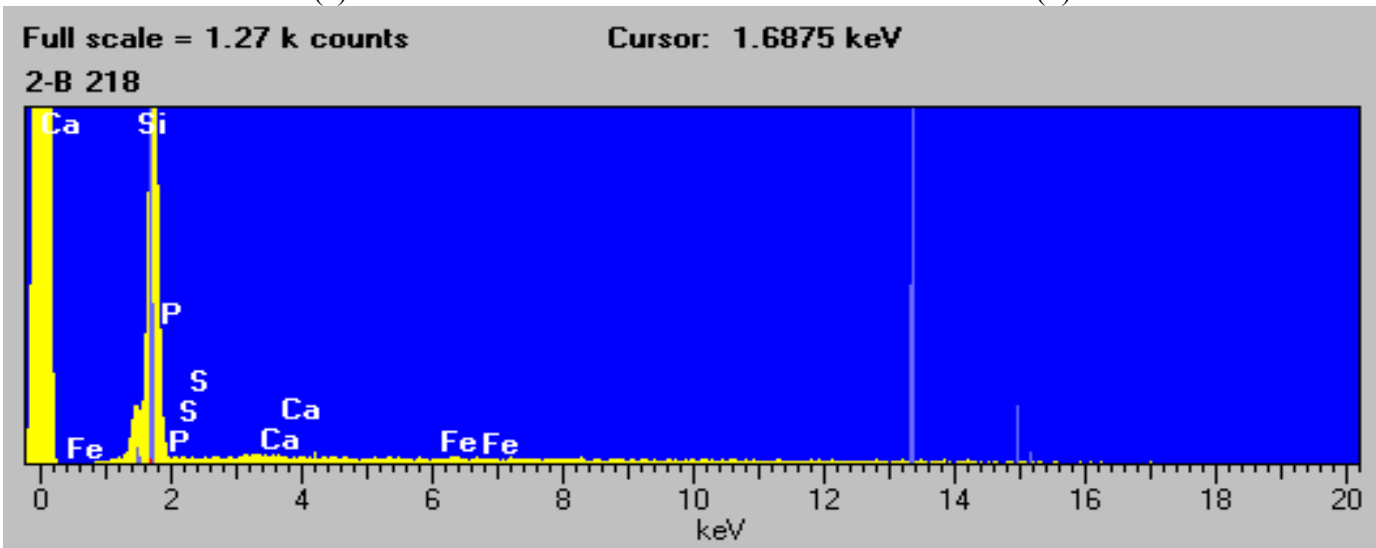

(c)

Fig. 4 (a) and (b) SEM images of historic sandstone and (c) EDX spot analysis from image (a).

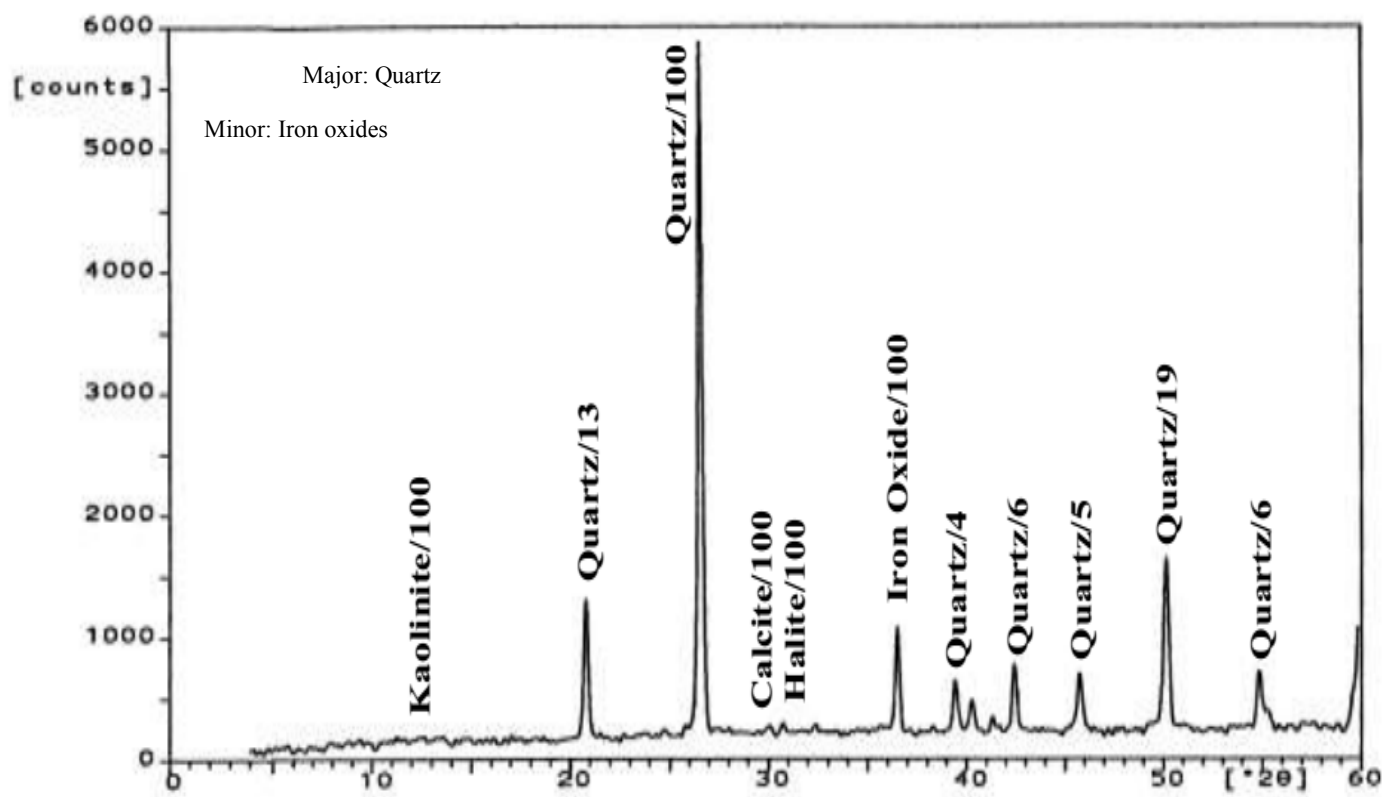

Fig. 5 XRD pattern of historic sandstone sample. 

Protection Materials for Highly Porous Artistic Stone

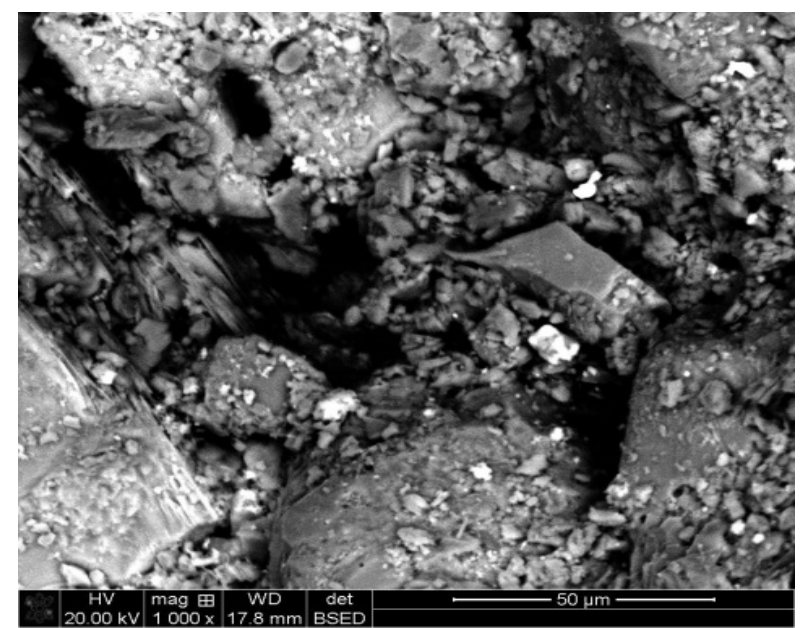

(a)

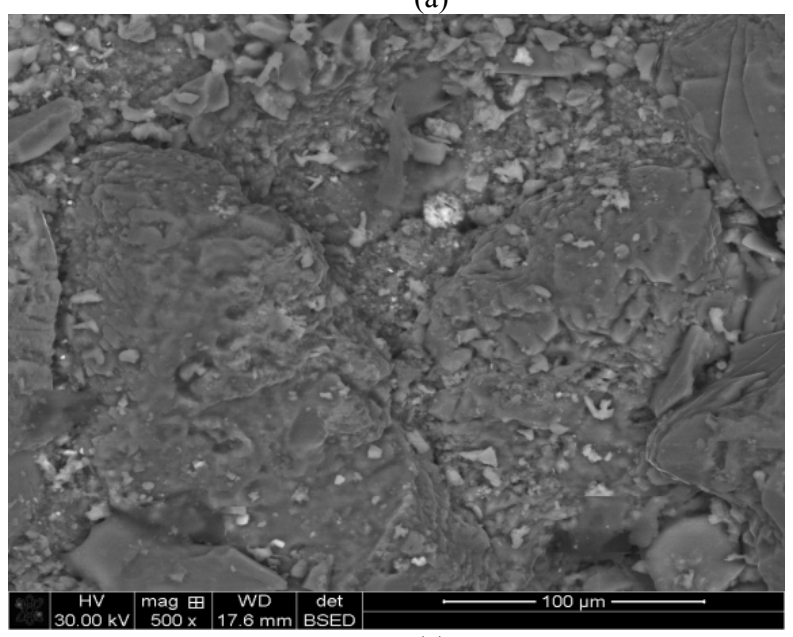

(c)

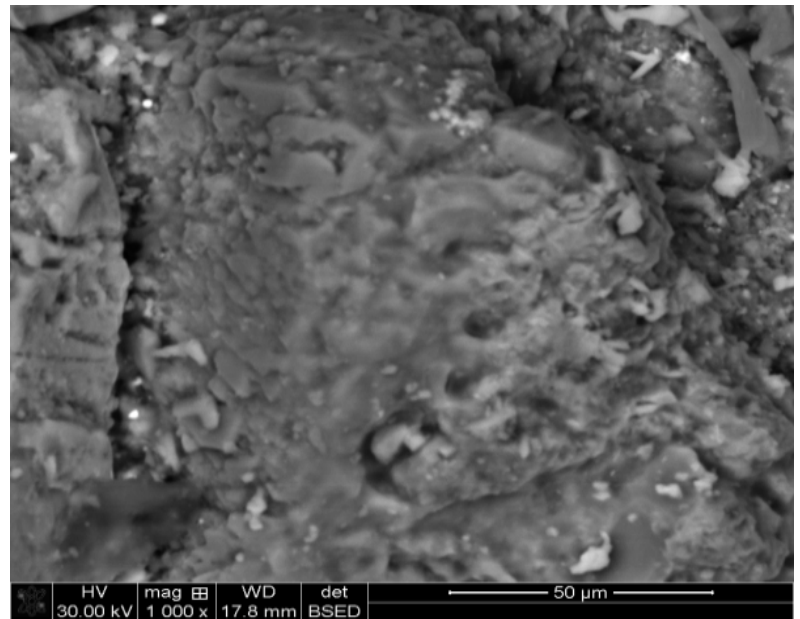

(b)

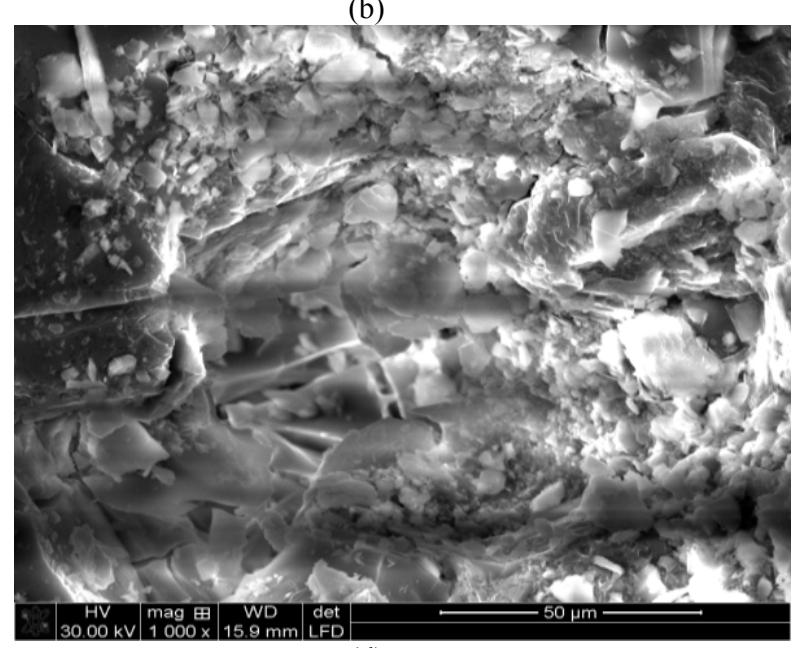

(d)

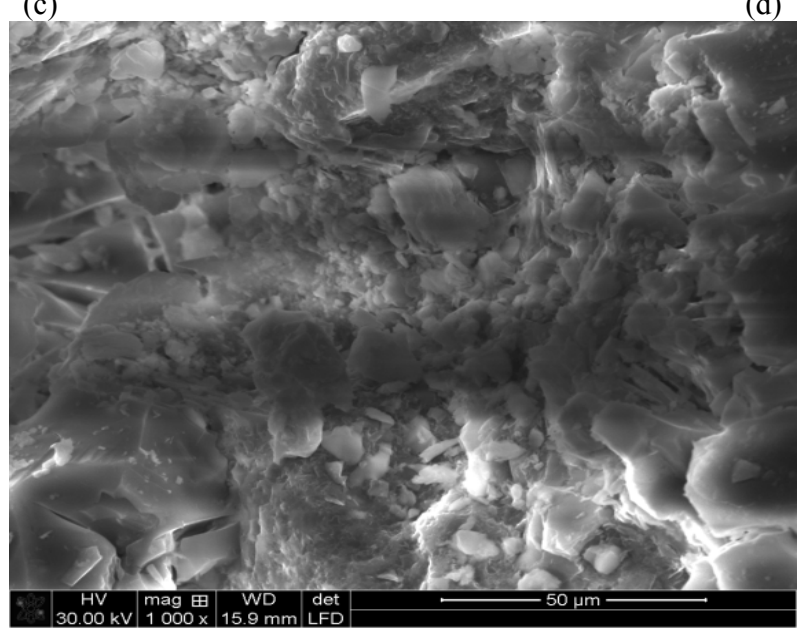

(e)

Fig. 6 Show the SEM micrographs of (a) untreated sample, (b) the sample treated with Pure SILRES® BS OH 100, (c) sample treated with $\mathrm{SiO}_{2}$ /polymer nanocomposites, (d) the samples treated with SILRES ${ }^{\circledR}$ BS OH 100 after thermal aging and (e) sample treated with $\mathrm{SiO}_{2} /$ polymer nanocomposites after thermal aging.

binding materials. SEM micrographs of samples treated with SILRES ${ }^{\circ}$ BS OH 100 (TEOS) in Fig. 6b showed that the treatment material succeeded in covering the sandstone grains and obscuring the boundaries between them. The network structure of consolidant can be seen dispersed between the grains 
and through the pores, but in some depth areas, the consolidant material has failed to fill the fine cracks.

On the contrary, the samples treated with $\mathrm{SiO}_{2} /$ polymer nanocomposites in Fig. 6c showed a homogeneous coating of the particles more than the coating with SILRES ${ }^{\circledR} \quad$ BS $\quad$ OH 100 without nanoparticles. Adding of nano silica to the consolidant material improved their interaction with the stone grains, in addition to increase their ability to fill the big pores between the grains.

After artificial thermal aging, some changes were observed in samples treated with both products. These changes were shown in the form of drought and shrinking of the polymer in some areas. Thermal aging also affected the film uniform and homogeneity which was illustrated further in samples treated with Pure TEOS. On the other hand, in the samples treated with TEOS containing $\mathrm{SiO}_{2}$ nanoparticles, no significant changes were observed in the consolidants film. This proved the stability of microstructure of the product under the effect of the artificial thermal aging compared to those coated with TEOS without the nanoparticles in Figs. 6d and 6e. This may be due to the fact that the unique physical and chemical properties, size and the higher surface area of the nanoparticles.

3.2.2 Physical and Mechanical properties before and after Artificial Aging

The physical and mechanical properties of studied stones were determined before and after treatment with both products and after artificial aging. It is evident from the average values of compressive strength that, the addition of nanoparticles to the polymers increases their compressive strength values.

After artificial thermal aging, the results indicated that, $\mathrm{SiO}_{2}$ nanoparticles increase the mechanical properties and stability of the polymer under weathering and studied conditions. The effect of treatment is higher when adding $\mathrm{SiO}_{2}$ nanoparticles, comparing to the samples treated with SILRES ${ }^{\circledR}$ BS OH 100 (TEOS) without nanoparticles. Completed data were listed in Table 1.

On the other hand, the physical measurements indicated that the treated samples were higher in their bulk density. The water absorption values of the samples treated with pure polymers and nanocomposites proved that the addition of nanoparticles to the polymers led to reduce their water absorption rates.

The efficiency of the silica/polymer nanocomposite in formation of a protective layer appears from the reduction in water absorption and porosity, which can be referred to the penetration of the silica nanoparticles into voids and pores [38]. The improvement of mechanical and physical properties reflects the importance of adding silica nanoparticles in consolidation processes. Table 2 shows the average values of water absorption for the untreated, treated and treated aged sandstone samples.

Table 1 Average values of compressive strength for untreated, treated and treated aged sandstone samples.

\begin{tabular}{lll}
\hline \multirow{2}{*}{ Applied consolidants materials } & & Compressive strength $\mathrm{cm}^{2} / \mathrm{Kg}$ \\
\cline { 2 - 3 } & After treatment & After treatment and thermal aging \\
\hline Untreated samples & 104 & 95 \\
Wacker OH100 (TEOS) & 203 & 194 \\
$\mathrm{SiO}_{2} /$ Polymer nanocomposites & 229 & 226 \\
\hline
\end{tabular}

Table 2 Average values of water absorption for treated and aged sandstone samples.

\begin{tabular}{lllllll}
\hline \multirow{3}{*}{ Applied consolidants materials } & \multicolumn{3}{c}{ After treatment } & \multicolumn{3}{c}{ After treatment and thermal aging } \\
\cline { 2 - 7 } & $\begin{array}{l}\text { Density } \\
\text { gm/cm }\end{array}$ & $\begin{array}{l}\text { Porosity } \\
\%\end{array}$ & $\begin{array}{l}\text { Water absorption } \\
\%\end{array}$ & $\begin{array}{l}\text { Density } \\
\text { gm/cm }\end{array}$ & $\begin{array}{l}\text { Porosity } \\
\%\end{array}$ & $\begin{array}{l}\text { Water absorption } \\
\%\end{array}$ \\
\hline Untreated samples & 2.40 & 21.9 & 8.8 & 2.40 & 21.9 & 8.8 \\
Wacker OH100 (TEOS) & 2.45 & 11.8 & 4.4 & 2.41 & 13.5 & 5.3 \\
$\mathrm{SiO}_{2}$ /Polymer nanocomposites & 2.54 & 9.4 & 3.9 & 2.51 & 10.2 & 4.2 \\
\hline
\end{tabular}




\subsubsection{Colorimetric Measurements}

Treated and treated aged stone surfaces were investigated in order to assess the colour variations with respect to untreated samples. According to Italian guidelines for the restoration of stone monuments, the $\Delta E$ value must be $<5$. The colour modification $(\Delta \mathrm{E})$ was calculated using the following relation:

$$
\Delta E=\sqrt{\Delta L^{* 2}+\Delta a^{* 2}+\Delta b^{* 2}}
$$

where, $\Delta L^{*}, \Delta a^{*}$ and $\Delta b^{*}$ are the differences in the $L^{*}$, $a^{*}$ and $b^{*}$ coordinates (according to CIEL AB color space) of the treated and untreated sandstone samples.

Such parameter is important for aesthetic reasons, in order to preserve the original colour of surfaces. After treatment and aging, negligible colour variations were observed, and all values are in acceptable limit ( $\Delta E$ value $<5$ ), thus confirming the suitability of the product for restoring purposes. The obtained data are fully listed in Table 3.

\subsubsection{Salt Migration to Stone Surface}

The migration of a salt to the surface of a porous stone material, is one of the most serious deterioration factors. The only way to completely and permanently prevent efflorescence in historical porous materials is by using special admixtures.

In fact, the nanomaterials in these additives can be up to 100,000 times smaller than even the smallest sand particles. This allows their molecules to literally pass sand particles and ultimately become part of the sand with which they react and protect porous building materials against salt efflorescence. The results showed that, the treated samples had a greater resistance to damage than the untreated samples. This was evaluated through the weighing of material lost. Following the salt weathering tests, the surfaces of the samples were visually observed. While the untreated samples had a powdery rough texture, the samples treated with $\mathrm{SiO}_{2}$ /polymer nanocomposite had a smoother surface with less deterioration visible, compared to those coated with TEOS without the nanoparticles, see Figs. 7a-7c.

Table 3 Color measurements in treated and aged samples.

\begin{tabular}{lllllllll}
\hline \multirow{2}{*}{ Applied consolidation materials } & \multicolumn{3}{c}{$\Delta$ (Treated and untreated samples) } & \multicolumn{3}{c}{$\Delta$ (Thermal aged and untreated samples) } \\
\cline { 2 - 8 } & $\Delta L^{*}$ & $\Delta a^{*}$ & $\Delta b^{*}$ & $\Delta E$ & $\Delta L^{*}$ & $\Delta a^{*}$ & $\Delta b^{*}$ & $\Delta E$ \\
\hline SILRES ${ }^{*}$ BS OH 100 & -1.91 & -0.91 & -1.42 & 2.55 & 1.40 & 0.18 & -4.26 & 4.49 \\
$\mathrm{SiO}_{2}$ /Polymer nanocomposites & -0.53 & 0.52 & 1.49 & 1.66 & 3.39 & 0.48 & 1.85 & 3.89 \\
\hline
\end{tabular}

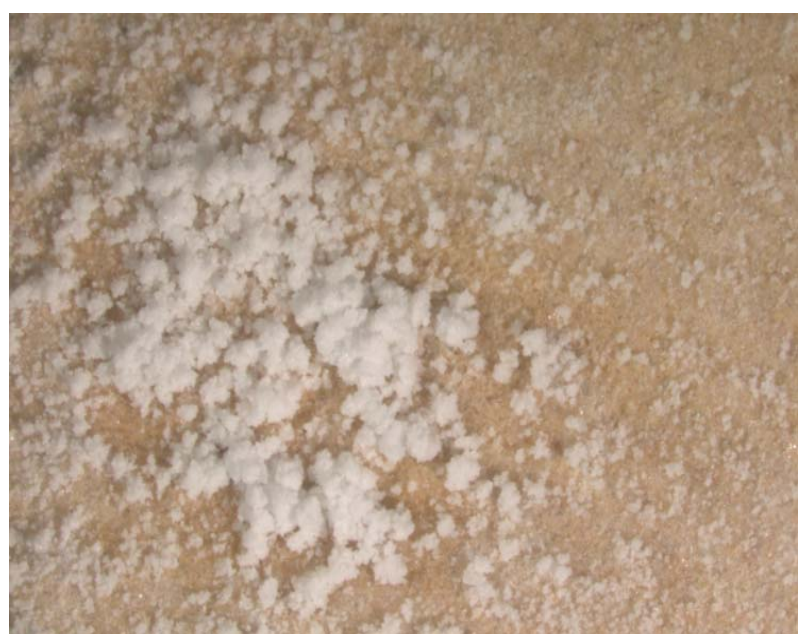

(a)

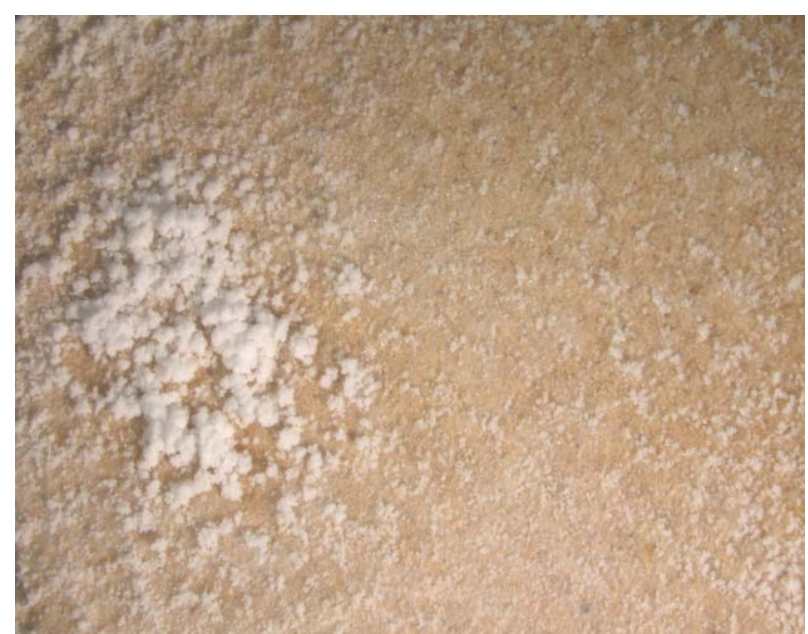

(b) 


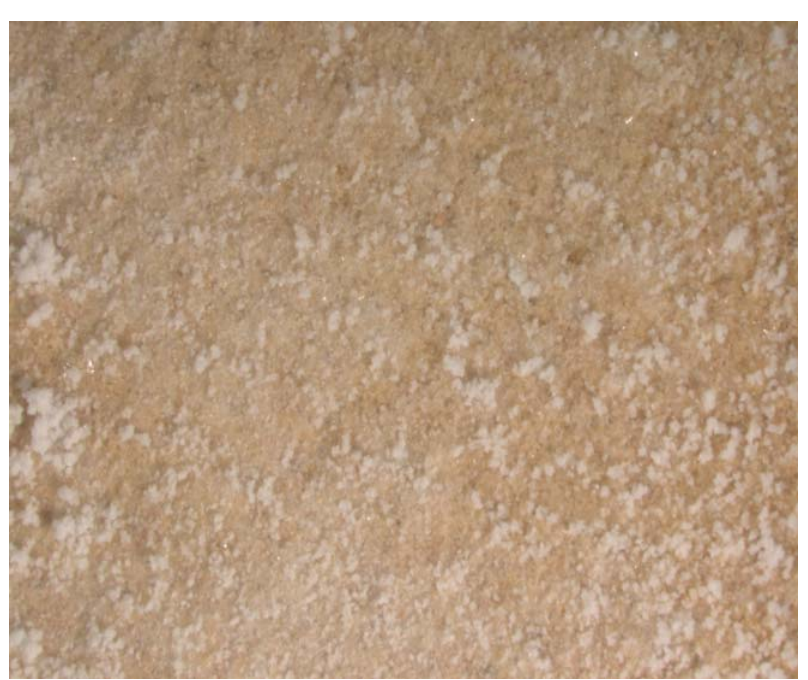

(c)

Fig. 7 Sterio microscopy images, Show the effect of the salt weathering on (a) untreated samples, (b) samples treated pure SILRES ${ }^{\circledR}$ BS OH 100 and (c) samples treated with $\mathrm{SiO}_{2} /$ polymer nanocomposite.

\section{Conclusions}

The damage and deterioration of the historical buildings due to their prevalently outdoor location, is a one of serious problems that attracts the researcher and conservator efforts all over the world.

In this study, silica nanoparticles were added to SILRES ${ }^{\circledR}$ BS OH 100 to produce new nanocomposite with hydrophobic and consolidation properties in order to improve its physiochemical and mechanical properties, and to obtain a consolidation and protection material used on historic artistic/ architectural stone.

Experimental samples treated with (SILRES ${ }^{\circledR}$ BS $\mathrm{OH} 100)$ and $\mathrm{SiO}_{2}$ nanoparticles/polymer nanocomposites were tested under artifial thermal aging and salt weathering. The results showed that the addition of nanoparticles to the silicon-based polymers improved their ability to consolidate and protect the sandstone samples. The results obtained by colorimetric test showed that, both products did not cause any great variations in original color after treatment and aging and negligible color variations were observed, i.e., all values are in acceptable limit. Moreover, samples treated with nanocomposites improved resistance to $\mathrm{RH} /$ temperature compared to that treated with the silicon polymer without $\mathrm{SiO}_{2}$ nanoparticles. The results of physical and mechanical properties for bare stones and after treatment indicated the efficiency of nanocomposite in protection and consolidation process, compared to the untreated samples or those treated with silicon polymer without $\mathrm{SiO}_{2}$ nanoparticles.

Moreover, adding of $\mathrm{SiO}_{2}$ nanoparticles to the consolidant material improved its interaction with the stone grains, in addition to increase its ability to fill the big pores between the grains and enhanced the durability of the polymer under the simulated weathering and artificial aging. This can be attributed to the compatibility and homogeneity between silica nanoparticles and the chemical composition of sandstone and silicone polymers.

In terms of multifunctional features, consolidation and photoactive, the treatment with $\mathrm{SiO}_{2} /$ polymer nanocomposites gave a better result, and should be used in the consolidation and protection of the fragile and sandstone monuments, especially which were built in desert areas. While there is still need to check their effectiveness on different stone species. However, a deeper analytical study focusing on the efficiency of the selected products under the salt and acid crystallization and varying the humidity and temperature conditions are currently under way. 


\section{References}

[1] Angelini, E., Grassini, S., Solorzano, G., Campos, G. D., Nascimento, G. Do. and Caro, T. De. 2006. "Integrated Approach to the Characterization and Conservation of Artifacts of the Brazilian Colonial Period." Applied Physics A-Materials Science \& Processing 83: 485-91.

[2] Saleh, S. A., Helmi, F. M., Kamal, M. M. and El-Banna, A. E. 1992b. "Study and Consolidation of Sandstone: Temple of Karnak, Luxor, Egypt." Studies in Conservation 37 (2): 93-104.

[3] Amoroso, G. and Fassina, V. 1983. Stone Decay and Conservation: Atmospheric Pollution, Cleaning, Consolidation and Protection. Materials Science Monographs, 11. Elsevier: Amsterdam and New York, 95-100.

[4] Van Grieken, R., Delalieux, F. and Gysels, K. 1998. "Cultural heritage and the Environment." Pure Appl. Chem. 70: 2327-31.

[5] Albertano, P. 1995. In Proceedings of 1st International Congress of Science and Technology for the Safeguard of Cultural Heritage in Mediterranean Basin, 1303-8.

[6] Ditaranto, N., Loperfido, S., van der Werf, I., Mangone, A., Cioffi, N. and Sabbatini, L. 2011. "Synthesis and Analytical Characterisation of Copper-Based Nanocoatings for Bioactive Stone Artworks Treatment." Anal Bioanal Chem. 399: 473-81.

[7] Mosquera, M. J., Pozo, J., Esquivas, L., Rivas, T. and Silva, B. 2002. "Application of Mercury Porosimetry to the Study of Xerogels Used as Stone Consolidants." $J$ Non-Cryst Solids 311: 185-94

[8] Zàrraga, R., Alvarez-Gasca, D. E. and Cervantes, J. 2002. "Solvent Effect on TEOS Film Formation in the Sandstone Consolidation Process." Silicon Chemistry 1: 397-402.

[9] Lugli, S., Minghelli, S. and Zannini, P. 2013. "Barium Silicate Consolidation of Historical Sandstones.” In Built Heritage: Monitoring Conservation Management, 1178-83.

[10] Winkler, E. M. 1970. "Decay of Stone." In Conservation of Stone and Wooden Objects, Vol. 1, Stone, ilC, London, 1-14.

[11] Helmi, F. M. 1985. "Deterioration of Stone Granite in Egypt." In Proceeding of $V^{\text {th }}$ Int. Congr. On Deterioration and Conservation of Stone, Vol. 1, Lausanne, 421-30.

[12] Helmi, F. M. 1988. "Deterioration Phenomenon in the North Temple Karanis (Near Fayoum), Egypt." In Proceeding of $\mathrm{Vl}^{\text {th }}$ Int. Congr. On Deterioration and Conservation of Stone, Torun, 166-74.

[13] Petuskey, W. T., Richardson, D. A. and Dolske, D. A. 1995. "Aspects of the Deterioration of Sandstone
Masonry in Anasazi Dwelling Ruins at Mesa Verde National Park, Colorado, USA." The Science of the Total Environment 167: 145-59.

[14] Hosono, T., Uchida, E., Suda, C., Ueno, A. and Nakagawa, T. 2006. "Salt Weathering of Sandstone at the Angkor Monuments, Cambodia: Identification of the Origins of Salts Using Sulfur and Strontium Isotopes." Journal of Archaeological Science 33 (11): 1541-51.

[15] Gulzar, S., Chaudhry, M. N., Burg, J. P. and Saeed, S. A. 2015. "Mughal Sandstone Heritage of Lahore: Formulating the Future Restoration Strategy." International Journal of Conservation Science 6 (2): 177-88.

[16] La Russa, M. F., Ruffolo, S. A., Rovella, N., Belfiore, C. M., Palermo, A. M. and Guzzi, M. T. et al. 2012. "Multifunctional $\mathrm{TiO}_{2}$ Coatings for Cultural Heritage." Progress in Organic Coatings 74: 186-91.

[17] Barthlott, W. and Neinhuis, C. 1997. "Purity of the Sacred Lotus, or Escape from Contamination in Biological Surfaces.” Planta 202: 1-8.

[18] Miliani, C., Velo-Simpson, M. L. and Scherer, G. W. 2007. "Particle-Modified Consolidants: A Study on the Effect of Particles on Sol-Gel Properties and Consolidation Effectiveness." Cult Heritage 8: 1-6.

[19] Manoudis, P., Karapanagiotis, I., Tsakalof, A., Zuburtikudis, I. and Panayiotou, C. 2008. "Super Hydrophobic Composite Films Produced on Various Substrates." Langmuir. 24 (19): 11225-32.

[20] De Ferri, L., Lottici, P., Lorenzi, A., Montenero, A. and Salvioli-Mariani, E. 2011. "Study of Silica Nanoparticles-Polysiloxane Hydrophobic Treatments for Stone-Based Monument Protection.” Journal of Cultural Heritage 12: 356-63.

[21] Kapridaki, C. and Maravelaki-Kalaitzaki, P. 2013. " $\mathrm{TiO}_{2}-\mathrm{SiO}_{2}$-PDMS Nano-Composite Hydrophobic Coatings with Self-Cleaning Properties for Marble Protection." Progress in Organic Coatings 76 (2-3): 400-10.

[22] La Russa, M. F., Rovella, N., Alvarez de Buergo, M., Belfiore, C. M., Pezzino, A. and Crisci, G. M. et al. 2016. "Nano- $\mathrm{TiO}_{2}$ Coatings for Cultural Heritage Protection: The Role of the Binder on Hydrophobic and Self-Cleaning Efficacy." Progress in Organic Coatings 91: 1-8.

[23] Tarasov, V. I. 2001. "New Colloid Silicate Solutions for Restoration and Conservation of Stone Facades." Russian J Appl Chem. 74 (12): 1985-9.

[24] Manoudis, P., Papadopoulou, S., Karapanagiotis, I., Tsakalof, A., Zuburtikudis, I. and Panayiotou, C. 2007. "Polymer-Silica Nanoparticles Composite Films as Protective Coatings for Stone-Based Monuments." Journal of Physics: Conference Series 61: 1361-5. 


\section{Protection Materials for Highly Porous Artistic Stone}

[25] Schindler, C. 2005. "Investigation of Consolidation Materials for Volcanic Tuff." Biuletyn Informacyjny Konserwatorów Dziet Sztuki 16 (1): 41-7.

[26] Mosquera, M. J., Santos, D. M. and Montes, A. 2004. "Producing New Stone Consolidants for the Conservation of Monumental Stones." In Materials Research Society Symposium, Materials Issues in Art and Archaeology VII, 3: 81-7.

[27] Zendri, E., Biscontin, G., Nardini, I. and Riato, S, 2007. "Characterization and Reactivity of Silicatic Consolidants." Construction and Building Materials 21: 1098-106.

[28] Valeria, D., Giuliana, T. and Raimondo, Q. 2008. "The Nanolimes in Cultural Heritage Conservation: Characterization and Analysis of the Carbonatation Process." Journal of Cultural Heritage 9 (3): 294-301.

[29] Shashaua, S. 1993. Mechanical Testing of Resins for USE in Conservation. ICOM Committee for Conservation, Washington, 58.

[30] Khallaf, M. K., El-Midany, A. A. and El-Mofty, S. E. 2011. "Influence of Acrylic Coatings on the Interfacial, Physical, and Mechanical Properties of Stone-Based Monuments." Progress in Organic Coatings 72: 592-8.
[31] EN 12370. 2000. Natural Stone Test Methods Determination of Resistance to Salt Crystallisation.

[32] Schanda, J. 2007. Colorimetry. Wiley-Interscience John Wiley \& Sons Inc, 56.

[33] Raccomandazioni NorMal. 1993. AA VV Raccomandazioni NorMal 43/93, Misure colorimetric he strumentali di superficiopache Roma. CNR-ICR.

[34] UNI 10859. 2000. Cultural Heritage - Natural and Artificial Stones - Determination of Water Absorption by Capillarity, Protocol.

[35] UNI 10921. 2001. Evaluation of the Efficacy of Water Repellent Treatments Applied on Stone Materials of Cultural and Artistic Interest, Protocol.

[36] Pinto, A. P. F. and Rodrigues, J. D. 2008. "Stone Consolidation: The Role of Treatment Procedures." Journal of Cultural Heritage 9: 38-53.

[37] ASTM C 170. 1976. Standard Test Methods for Compressive Strength of Natural Building Stone.

[38] Choi, J., Park, S., Won, J., Choi, Y. S., Kang, Y. S. and Lee, M. S. 2012. "Effect of Pretreatment for TEOS Based Stone Consolidants." In Proceeding of 12th International Congress on the Deterioration and Conservation of Stone, Columbia University, New York, 119-28. 